\title{
CONVOLUTION PROBLEMS IN TIME-RESOLVED X-RAY DIFFRACTION
}

\author{
S. BRATOS, J.-CL. LEICKNAM
}

\author{
PACS 61.10.Eq, 78.47. + p, \\ Laboratoire de Physique Théorique de la Matiére Condensée, \\ Université Pierre et Marie Curie, Case courrier 121 \\ 82.53.Eb \\ (4, Place Jussieu, Paris 75252, Cedex 05, France)
}

Convolution problems in the time-resolved scattering of 10-1000ps x-ray pulses are studied theoretically. The model system is a diluted solution of diatomic molecules $\mathrm{A}_{2}$ dissolved in an inert solvent. This system is submitted to a sub-picosecond laser pulse, which promotes the molecules $\mathrm{A}_{2}$ into an excited electronic state. The molecule then return into their ground state, passing through several intermediate electronic states. The effects of the finite duration of probing x-ray pulses on various x-ray signals are then examined in the frame of this model. Unbiased signals generated by very short $\mathrm{x}$-ray pulses are explored first. Variations of a molecular geometry during this process are clearly visible in $r$-resolved, but are less explicit in $q$-resolved signals. The signals measured with x-ray pulses of a finite duration are studied next. Atomic motions remain detectable, but only if the x-ray pulses are shorter than or comparable to the times of a molecular dynamics. Here again, the $r$-resolved signals are more appropriate for monitoring the molecular dynamics than $q$-resolved signals. Finally, the effect of the insufficient temporal location of probing x-ray pulses with respect to that of exciting laser pulses is examined. It is shown that this last effect can be accounted for by simply replacing the true x-ray pulse intensity by another theoretically predicted intensity. The similarity of deconvolution techniques in spectroscopy and in time-resolved x-ray diffraction is strongly emphasized.

\section{Introduction}

The distortion of signals recorded due to imperfect recording devices is omnipresent in experimental sciences. This is particularly well known in optical spectroscopy, where spectral lines are deformed by the finite slit width of a spectrometer. This deformation may be large enough to compromise the interpretation of the observed data. It is thus particularly important to eliminate these errors, which can be done employing a technique called deconvolution (as for linear and modern nonlinear techniques in this field, see [1]). For the recent publications in this area, see [2-4].

Similar problems are also present in other fields of experimental sciences such as astrophysics, geophysics, chemical analysis by electronic spectroscopy, and cell biology. Somewhat surprisingly, the deconvolution tech- niques are also useful to improve the quality of optical images. For example, the quality of a camera may be improved, at a given cost of optical elements, by incorporating appropriate deconvolution devices [1]. Another example is the Hubble space telescope, where the initial flaws of its mirror were partially corrected using the deconvolution techniques [1]. The deconvolution problems are thus omnipresent in experimental sciences.

It is then not too surprising that they also occur in time-resolved x-ray diffraction and absorption. For some reviews covering this field, see [5-7]. However, here they are not related to a finite slit width of spectrometers, but to a finite duration of probing x-ray pulses. The latter are generated by large scale instruments such as synchrotrons or linear accelerators with free electron lasers. Many questions can be asked, and the purpose of this paper is to answer some of them. How does a finite duration of x-ray pulses deform the experimental timeresolved x-ray signals? Which artifacts appear when these pulses are too long? How can the deconvolution problems in x-ray and in spectroscopic experiments be compared? In what follows, these questions will be examined theoretically. The similarity of the deconvolution techniques in x-ray physics and in spectroscopy is emphasized.

\section{Basic Considerations}

(A) The experiments under consideration are timeresolved x-ray diffraction experiments (Fig. 1). The liquid under consideration is pumped by a laser, which promotes a fraction of molecules into an excited quantum state. The further behavior of this system is probed using a series of time-delayed $\mathrm{x}$-ray pulses. In liquids and disordered systems, the resulting diffraction patterns consist of circular rings centered on the forward beam. If a reaction takes place, these diffraction patterns vary with time. A collection of experimentally measured x-ray patterns can be transformed into a collection of molecular photographs by the Fourier sine transforma- 

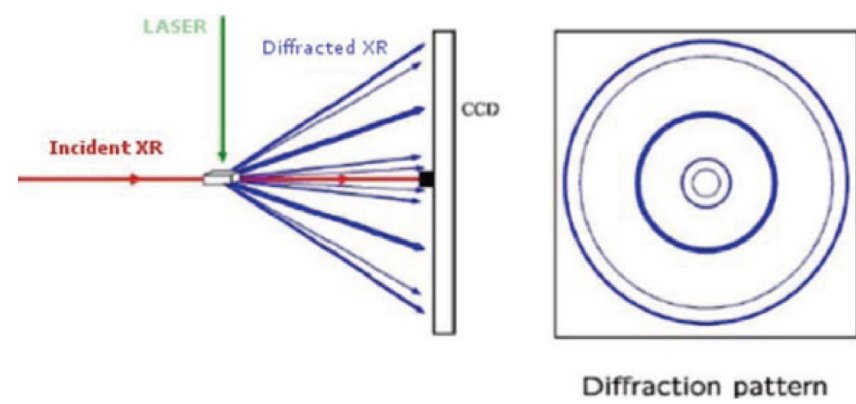

Fig. 1. Schematic representations of the experimental set-up (left) and the observed x-ray diffraction pattern (right)

tion. Atomic motions during a chemical reaction can be filmed by proceeding in this way.

(B) The central equation relating the measured x-ray signal $\Delta S(q, \tau)$, the true x-ray signal $\Delta S_{\text {inst }}(q, t)$ free of any distortion, and the x-ray pulse intensity $I_{x}(t)$ has the form of a convolution integral. First proposed intuitively [8] and later proven theoretically $[9,10]$, it reads

$\Delta S(q, \tau)=\int d t I_{x}(t-\tau) \Delta S_{\mathrm{inst}}(q, t)$.

Here, the signal $\Delta S(q, \tau)=S(q, \tau)-S(q)_{\text {eq }}$ describes the energy flux $S(q, \tau)$ of the diffracted x-ray radiation scattered in a solid angle in the presence of a pump minus the equivalent quantity $S(q)_{\text {eq }}$ in the absence of a pump, $q$ is the scattering wave vector, and $\tau$ is the time elapsed between the pumping optical and probing x-ray pulses. The signal $\Delta S_{\text {inst }}(q, t)=S_{\text {inst }}(q, t)-S(q)_{\text {eq }}$ is defined similarly, except that the incident x-ray pulse is assumed to be infinitely short. The important signal $\Delta S_{\text {inst }}(q, t)$ cannot be measured, unfortunately, directly. It can be deduced from the experimental $\Delta S[q, \tau)$ by deconvolution (compare with Eq. (1)). One is thus faced with the same problem as spectroscopists, although not for the same reason.

(C) The measured signals $\Delta S(q, \tau), \Delta S_{\text {inst }}(q, t)$ are not related to a molecular geometry directly, and the Fourier transformation of these signals is necessary. This statement is valid under static and quasistatic conditions. It is thus useful to introduce the quantities

$\Delta S[r, \tau]=1 / 2 \pi^{2} r \int d q q M(q) \Delta S(q, \tau) \sin (q r)$,

$\Delta S_{\text {inst }}[r, t]=1 / 2 \pi^{2} r \int d q q M(q) \Delta S_{\text {inst }}(q, t) \sin (q r)$

The function $\Delta S_{\text {inst }}[r, t]$ is a linear combination of the atom-atom distribution functions $g_{i j}(r, t)$ [11], which in- dicate the probability to find atoms $i$ and $j$ at a distance $r$ at time $t$. The quantity $\Delta S_{\text {inst }}[r, t]$ is related to the geometry of the system and the atomic motion in films during a chemical reaction. Only if the molecular motions are slow as compared with the x-ray pulse, the signal $\Delta S[r, \tau]$ can be assimilated to $\Delta S_{\text {inst }}[r, t]$. If not, a finite pulse duration blurs molecular films noticeably.

(D) In order to connect the present x-ray study to more familiar optical studies, it seems useful to present the terminology used in convolution theory [1]. The convolution integral is generally written in the form $i(x)=\int d x^{\prime} s\left(x-x^{\prime}\right) o\left(x^{\prime}\right)$, where $i(x)$ is called "intensity", $s\left(x-x^{\prime}\right)$ is the "point spread function," and $o\left(x^{\prime}\right)$ is an "object". In spectroscopy, $x, x^{\prime}$ are frequencies $\omega, \omega^{\prime}, i(x)$ is the observed band intensity $I(\omega)$, $s\left(x-x^{\prime}\right)$ is the apparatus function, and $o(x)$ the true band intensity $J\left(\omega^{\prime}\right)$. In time-resolved x-ray diffraction, $x$ and $x^{\prime}$ are times $\tau$ and $t, i(x)$ are the observed diffraction signals $\Delta S(q, \tau)$ or $\Delta S[r, t], s\left(x-x^{\prime}\right)$ is the x-ray beam intensity $I_{x}(t-\tau)$, and $o(x)$ are the true x-ray signals $\Delta S_{\text {inst }}(q, t)$ or $\Delta S_{\text {inst }}[r, t]$. These notions should be kept in mind to compare the deconvolution problems in spectroscopy and in x-ray diffraction.

\section{Model System}

A. As the purpose of the present paper is to study spurious effects from insufficiently short synchrotron pulses, our attention will be focused on events occurring between 1 and 100 ps. We thus decided to examine fast processes taking place, when a diluted solution of diatomic molecules $\mathrm{A}_{2}$ is excited by a laser. It is sufficient in reality to study the contribution to the $\mathrm{x}$-ray signal due to the solute molecule $\mathrm{A}_{2}$ alone. In fact, there exist the procedures allowing one to eliminate the solvent part in the measured x-ray signal experimentally [12]. What remains is proportional to a weighted sum of terms associated with the atom pairs $A A, A B, A C \ldots$, where $A$ denotes the solute atoms and $B, C \ldots$ stand for the solvent atoms. As these contributions usually peak in separate regions of the $r$-space, the signal of the $A A$ pair can often be isolated. Note that $\Delta S_{\text {inst }}[r, t]$ is then simply proportional to the $A A$ pair distribution function, $g_{A A}(r, t)$.

B. Our model is inspired by laser spectroscopy of halogen diatomics [13-15] and can be described as follows. The states $X$ and $Y$ of the dissolved molecule $\mathrm{A}_{2}$ are attractive, whereas the state $Z$ is repulsive (Fig. 2). The equilibrium $A-A$ distances are $r_{X}$ and $r_{Y}$ in the states 
$X$ and $Y$. From the other side, the potential energy curves of the electronic states $Y$ and $Z$ are assumed to cross each other at a distance $r_{Y}+\Delta r_{Y}$. A molecule $\mathrm{A}_{2}$ is submitted to an ultrafast laser pulse, which brings it to the repulsive state $Z$. The transition is supposed to be vertical, according to the Franck-Condon principle. Very rapidly, almost instantaneously, a laser-excited molecule reaches the crossing point $r_{Y}+\Delta r_{Y}$, where it switches from the state $Z$ to the state $Y$; two processes follow. The first of them is the passage of atoms $A$ in the state $Y$ of $\mathrm{A}_{2}$ from its extended configuration $r_{Y}+\Delta r_{Y}$ to its equilibrium configuration $r_{Y}$. It is accomplished in a time $\tau_{v}$ of the order of $100 \mathrm{ps}$. The second process is the deexcitation of $\mathrm{A}_{2}$ from the electronic state $Y$ to the ground electronic state $X$. It is much slower and is realized in times $\tau_{p}$ of the order of 1000 ps.

C. This model is now described theoretically. Let $g_{X}(r, t)$ and $g_{Y}(r, t)$ denote the $A-A$ atom distribution functions in the electronic states $X$ and $Y, g_{\text {eq }}(r)$ the $A-$ $A$ distribution function in equilibrium conditions, $n_{X}(t)$ and $n_{Y}(t)$ fractional populations of these two electronic states, $V$ the volume of the solution, and $P$ a factor depending on the geometry of the experimental set-up. The following expressions then describe our model:

$$
\begin{aligned}
& \Delta S_{\text {inst }}[r, t]=\left(e^{2} / m c^{2}\right)(P / V) \times \\
& \times\left\{n_{X}(t) g_{X}(r, t)+n_{Y}(t) g_{Y}(r, t)-g_{\mathrm{eq}}(r)\right\}, \\
& g_{X}(r, t)=g_{\mathrm{eq}}(r)=A \exp \left[-a_{X}\left(r-r_{X}\right)^{2}\right], \\
& g_{Y}(r, t)=B \exp \left[-a_{Y}\left(r-r_{Y}-\Delta r_{Y} \exp \left(-t / \tau_{v}\right)\right)^{2}\right], \\
& n_{X}(t)=1-n_{0} e^{-t / \tau p} ; \quad n_{Y}(t)=n_{0} e^{-t / \tau p} .
\end{aligned}
$$

They can be interpreted as follows. Equation (3) states that the signal $\Delta S_{\text {inst }}[r, t]$ is a superposition of the signals corresponding to the electronic states $X$ and $Y$. The short-lived electronic state $Z$ does not contribute to the signal on the time scales under consideration. On the other hand, according to Eq. (4b), the laser-excited $\mathrm{A}_{2}$ contracts in the state $Y$ intimes comparable to $\tau_{v}$. According to Eqs. (5), the population relaxation of $\mathrm{A}_{2}$ between the states $Y$ and $X$ is exponential with a characteristic time $\tau_{p}$. As said above, this process is assumed to be much slower than the contraction of $\mathrm{A}_{2}$ in the state $Y$. Unfortunately, as simple as the above $\Delta S_{\text {inst }}[r, t]$ may be, it does not lead to a simple analytical expression for

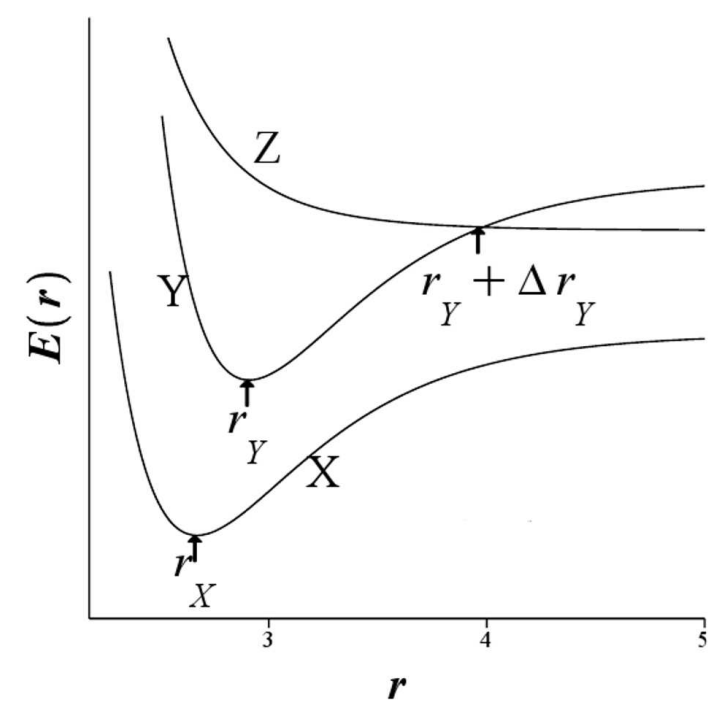

Fig. 2. Electronic energy surfaces of the molecule $\mathrm{A}_{2}$. The states $X$ and $Y$ are attractive, whereas the state $Z$ is repulsive. The equilibrium $A-A$ distance is $r_{X}$ in the state $X$, and $r_{Y}$ in the state $Y$. The energy surfaces of $Y$ and $Z$ cross each other at an $A-A$ separation equal to $r_{Y}+\Delta r_{Y}$. To make a crossing possible, the $Y$ and $Z$ states must have different symmetries. This crossing is supposed to be infinitely fast in the present model

$\Delta S_{\text {inst }}(q, t)$. To avoid additional uncertainties, we prefer to use the well-known exact relation, which connects $\Delta S_{\text {inst }}(q, t)$ and $\Delta S_{\text {inst }}[r, t][16]$ :

$\Delta S_{\mathrm{inst}}(q, t)=(4 \pi / q) \int d r r \Delta S_{\mathrm{inst}}[r, t] \sin (q r)$.

The function $\Delta S_{\text {inst }}(q, t)$ was then determined numerically.

D. The parameters of the above model were given as follows $[13-15,17,18]$ : the equilibrium $A-A$ distance $r_{X}$ is $2.5 \AA$, and $r_{Y}$ is $3.0 \AA$, whereas the laser-induced extension $\Delta r_{y}$ in the state $Y$ is $1.5 \AA$. In turn, the parameters $a_{X}$ and $a_{Y}$ are $10 \AA^{-2}$, which corresponds to a half-width of $g_{X}(r, t)$ and $g_{Y}(r, t)$ of the order of $0.3 \AA$. Moreover, the recombination time $\tau_{v}$ of the molecule $\mathrm{A}_{2}$ in its electronic state $Y$ is taken to be $100 \mathrm{ps,}$, whereas the lifetime $\tau_{p}$ of this state is supposed to be 1000 ps. These values of parameters will be maintained throughout this work. Only the form of the incident X-ray pulse will vary from one calculation to another.

E. This above model represents, in fact, a simplified version of that employed one to analyze the recombination of the laser-dissociated $\mathrm{I}_{2} / \mathrm{CCl}_{4}$ or $\mathrm{Br}_{2} / \mathrm{CCl}_{4}$ solutions [9-11]. The main difference between them is that the $A-A$ recombination is monoexponential here, whereas it was multiexponential in $\mathrm{I}_{2} / \mathrm{CCl}_{4}$. Moreover, the solvent cage problems of $\mathrm{I}_{2} / \mathrm{CCl}_{4}$ are avoided, by 


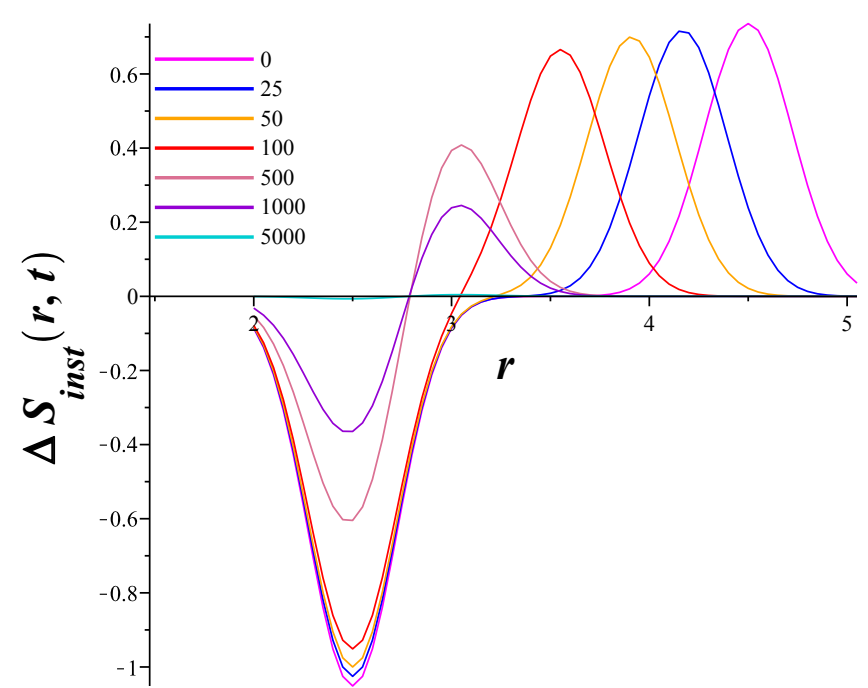

Fig. 3. Deconvoluted x-ray signals $\Delta S_{\text {inst }}[r, t]$, free of any instrumental deformation. They are presented for distances $r$ such that $2 \AA<r<5 \AA$ and for several times $t$ taken in the interval $0 \mathrm{ps}<t<5000 \mathrm{ps}$. The contraction of the laser-excited $\mathrm{A}_{2}$ is clearly visible on the positive peak of $\Delta S_{\text {inst }}[r, t]$, which shifts gradually from $4.5 \AA$ to $3 \AA$. Its negative peak around $2.5 \AA$ is due to the laser-generated hole in the ground-state population of $\mathrm{A}_{2}$

imposing a potential energy curve crossing at $r_{Y}+\Delta r_{Y}$ to $\mathrm{A}_{2}$ (Fig. 2). The characteristic times are also chosen similarly in both models; the present model is thus close to the physical reality. The convolution problems can be studied safely in its frame.

\section{Non-Distorted Signals $\Delta S_{\text {inst }}[r, t]$ and $\Delta S_{\text {inst }}(q, t)$}

The $r$-space signals $\Delta S_{\text {inst }}[r, t]$, free of any instrumental deformation, are presented first for $2 \AA<r<5 \AA$ and $0<t<5000$ ps (Fig. 3). They are vanishing at negative times as expected. This is a consequence of the causality principle: the consequence cannot precede the cause. These signals appear firstly at $t=0$ and exhibit two peaks. The positive peak at $r=4.5 \AA$ shows the presence of laser excited molecules $\mathrm{A}_{2}$ in an extended configuration of the state $Y$, where $r=r_{Y}+\Delta r_{Y}$. The negative peak at $r=2.5 \AA$ indicates that the molecules promoted to the state $Y$ are missing in the state $X$. At longer times, the positive peak shifts progressively from $4.5 \AA$ to $2.5 \AA$, monitoring the contraction of the photoelongated $\mathrm{A}_{2}$ in this way. Simultaneously, the negative peak at $r=2.5 \AA$ diminishes in its absolute value and vanishes in a few thousands of ps, when the thermal equilibrium is reestablished. This is how the return of a

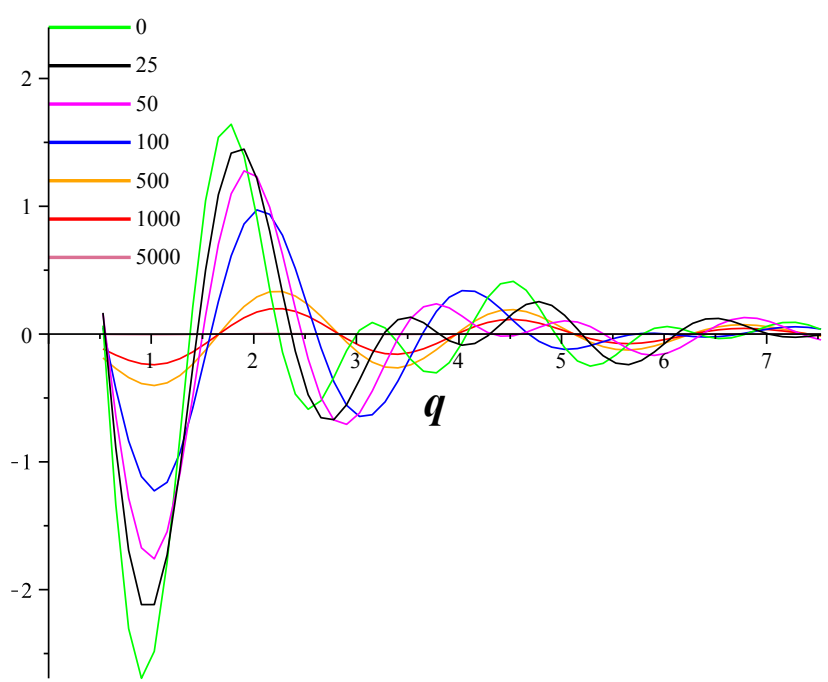

Fig. 4. Deconvoluted x-ray signals $\Delta S_{\text {inst }}(q, t)$ free of any instrumental deformation. They are presented for wave vectors $q$ such that $0.5 \AA^{-1}<q<7 \AA^{-1}$ and for several times $t$ taken in the interval $0 \mathrm{ps}<t<5000$ ps. The contraction of the laser-excited $\mathrm{A}_{2}$ manifests itself by high $q$ shifts of both signal maxima and minima. However, the variation of the signals $\Delta S_{\text {inst }}(q, t)$ is less prominent than that of $\Delta S_{\text {inst }}[r, t]$

laser-excited solution to the thermal equilibrium manifests itself in an ideal x-ray diffraction experiment.

The $q$-space signals $\Delta S_{\text {inst }}(q, t)$ are presented next for a domain, where $0.50 \AA<q<7 \AA^{-1}$ and $0<t<$ 5000 ps (Fig. 4). The calculated curves exhibit damped oscillations. Signals $\Delta S_{\text {inst }}(q, t)$ cross the $q$-axis at the points $q_{n}$ such that $\Delta q=q_{n+1}-q_{n} \sim \pi / r_{Z}$; here, $r_{Z}$ is a distance somewhere between $r_{X}$ and $r_{Y}+\Delta r_{Y}$. The intensity of $\Delta S_{\text {inst }}(q, t)$ decreases with time $t$; simultaneously, the peaks shift to higher values of $q$. This is expected, as the high $q$ shifts correspond to a contraction of the $A-A$ distance. However, they are comparatively small and do not exceed $0.6 \AA^{-1}$ in our calculation. One concludes that $q$-space signals are less convenient to monitor the molecular dynamics than $r$-space signals.

\section{Role of Duration of Probing X-ray Pulses}

A. The influence of the x-ray pulse duration on the shape of a measured x-ray signal is the central point of the present study. The incident x-ray pulses $I_{x}(t-\tau)$ will be written as a Gaussian centered at the time $\tau$, which is by no means a heavy restriction. Then $I_{x}(t-\tau)=$ $I_{0} \exp \left[-\alpha(t-\tau)^{2}\right]$, where $I_{0}$ is the amplitude of the $\mathrm{x}-$ ray pulse and $\alpha$ determines its duration.

B. The effect of x-ray pulses of finite duration is studied now. The functions $I_{X}(t-\tau)$ and $\Delta S_{\text {inst }}[r, t]$ are con- 

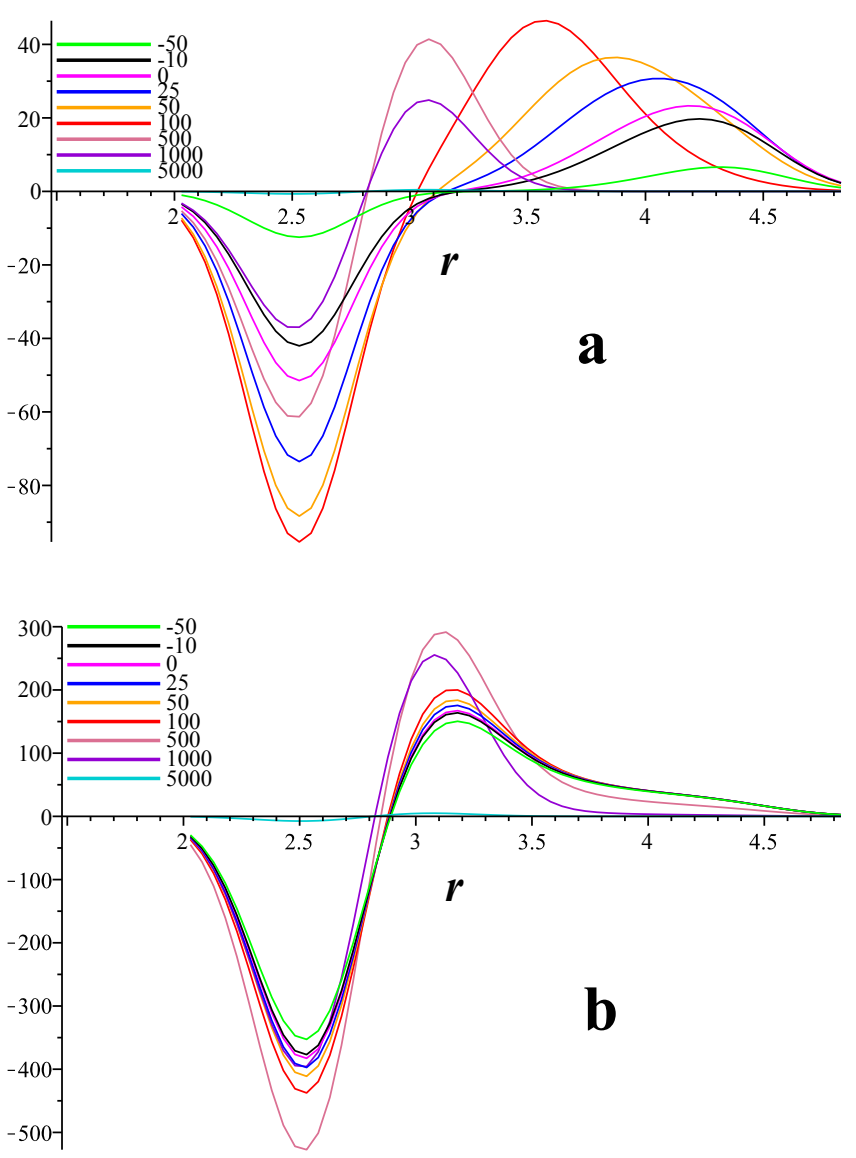

Fig. 5. Signals $\Delta S[r, \tau]$ calculated for x-ray pulses of finite width. They are presented for distances $r$ such that $2 \AA<r<5 \AA$ and for several pump-probe delays $\tau$ taken in the interval $-50 \mathrm{ps}<$ $\tau<5000 \mathrm{ps}$. The $\mathrm{x}$-ray pulse duration is $100 \mathrm{ps}$ in Fig. 5, $a$ and 1000 ps in Fig. 5,b. The contraction of $\mathrm{A}_{2}$ is clearly visible with $\mathrm{x}$-ray pulses of $100 \mathrm{ps}$ duration, but no longer for pulses of $1000 \mathrm{ps}$ duration

voluted to achieve this goal; the resulting signal $\Delta S[r, \tau]$ then corresponds to the experimental signal. This calculation was realized for $A-A$ separations $r$ in the interval $2 \AA<r<5 \AA$, and pump-probe time delays $\tau$ in the interval $-50 \mathrm{ps}<\tau<5000 \mathrm{ps}$. The results are illustrated in Figs. 5, $a, b$; the following remarks are worth noting. In Fig. $5, a$, the duration $\Delta \tau_{1 / 2}$ of the x-ray probe is the same as the time $\tau_{v}$ of contraction of the $A-A$ bond; one has $\Delta \tau_{1 / 2}=\tau_{v}=100 \mathrm{ps}$. Under these conditions, the signals $\Delta S_{\text {inst }}[r, t]$ and $\Delta S[r, t]$ are similar to each other; compare Figs. 3 and 5, a. However, the similarity does not mean the identity. For example, the band intensities are smaller here than the true band intensities. This similarity disappears in Fig. $5, b$, where $\Delta \tau_{1 / 2}=1000 \mathrm{ps}$ and $\tau_{v}=100 \mathrm{ps}$. In fact, if the x-ray pulse duration $\Delta \tau_{1 / 2}$ is long as compared to the contraction time $\tau_{v}$,
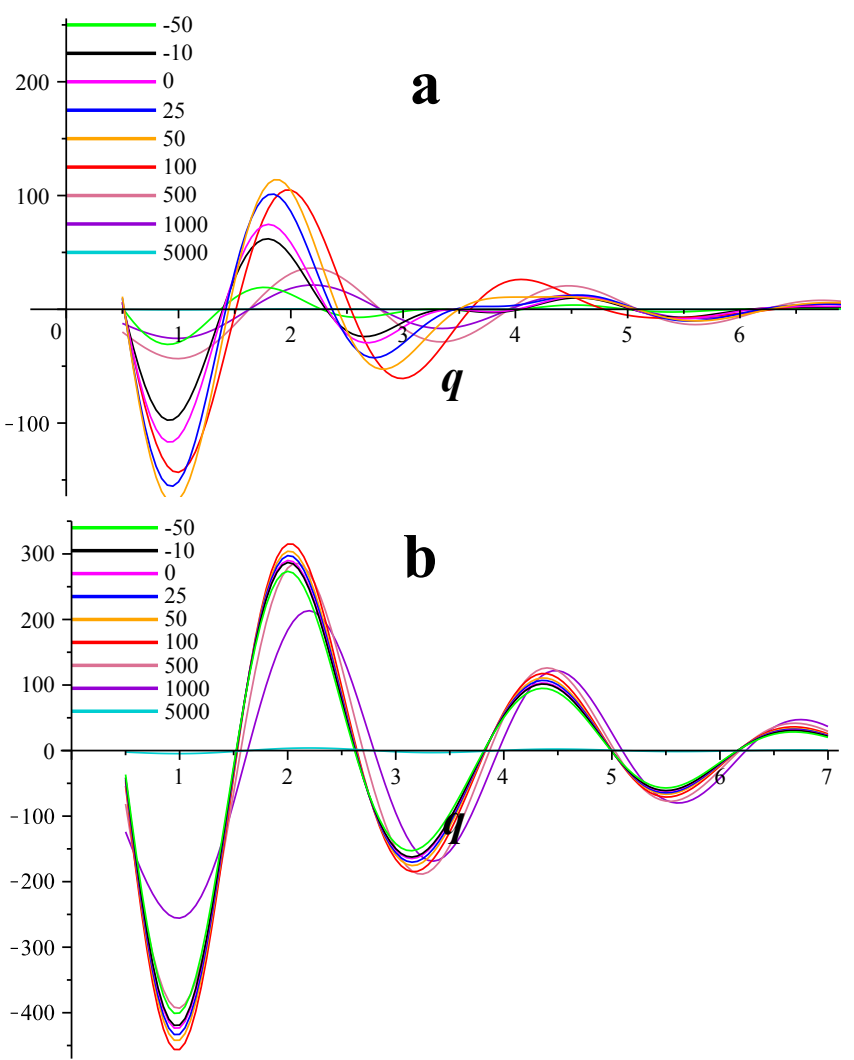

Fig. 6. Signals $\Delta S(q, \tau)$ calculated for x-ray pulses of finite width. They are presented for wave vectors $q$ such that $0.5 \AA^{-1}<q<$ $7 \AA^{-1}$ and for several pump-probe delays $\tau$ taken in the interval -50 ps $<\tau<5000$ ps. The x-ray pulse duration is 100 ps in Fig. 6, $a$ and 1000 ps in Fig. 6,b. The contraction of the laserexcited $\mathrm{A}_{2}$ manifests itself by high $q$ shifts of both signal maxima and minima. However, this effect is hardly detectable at $1000 \mathrm{ps}$

this probing pulse mainly monitors contracted molecules $\mathrm{A}_{2}$. This contraction process can only be "filmed" with x-ray pulses of duration $\Delta \tau_{1 / 2}$ comparable to or shorter than $\tau_{v}$. On the contrary, the slow population relaxation remains observable with longer pulses. This "collapse" of an x-ray signal, when the duration of probing $\mathrm{x}$-ray pulses increases, is a novelty for time-resolved $\mathrm{x}$ ray physics. However, it is not a novelty for general physics. In fact, a similar effect was observed and was carefully analyzed long time ago in NMR and in optics. It is well known under the name of motional narrowing; see, e.g., [19].

C. A similar study was realized in the $q$-space. The functions $I_{X}(t-\tau)$ and $\Delta S_{\text {inst }}(q, t)$ were convoluted to generate $\Delta S(q, \tau)$. The calculations were realized for wave vectors $q$ between $0.50 \AA^{-1}<q<7 \AA^{-1}$ and for pump-probe time delays $\tau$ in the interval $-50 \mathrm{ps}<\tau<$ 5000 ps. The results are illustrated in Figs. 6,a,b. The 
times $\Delta \tau_{1 / 2}$ and $\tau_{v}$ are the same in Fig. 6, $a$, whereas $\Delta \tau_{1 / 2} \gg \tau_{v}$ in Fig. 6,b. One finds that, when $\Delta \tau_{1 / 2}=$ $\tau_{v}$, the signals $\Delta S(q, \tau)$ of Fig. $6, a$ and $\Delta S_{\text {inst }}(q, t)$ of Fig. 4 are similar to each other, except for some blurring. In particular, the high $q$-shifts remain observable at short $\tau$ 's. This is less and less true for the signals $\Delta S(q, \tau)$ of Fig. 6,b, where $\Delta \tau_{1 / 2} \gg \tau_{v}$; dynamical effects are smaller in this case. The explanation of these findings is the same for $\Delta S[r, \tau]$. One concludes here again that $r$-resolved signals $\Delta S[r, \tau]$ are preferable for monitoring the molecular dynamics to $q$-resolved signals $\Delta S(q, \tau)$.

\section{Improper Location of the Origin of X-Ray Pulses}

We shall finally explore briefly the effect of an insufficiently precise temporal location of the probing x-ray pulse. The problem is not necessarily academic. A finite temporal width of probing x-ray pulses makes the measure of pump-probe time delays $\tau$ uncertain. In what follows, the laser pump pulse will be supposed to peak at the time $t=0$, precisely. On the contrary, the x-ray pulses will peak at a time $\tau_{0}$ which is not entirely under control. These pulses will be written as $I_{X}=I_{0} \exp \left[-\alpha\left(t+\tau_{0}-\tau\right)^{2}\right]$, where $\tau_{0}$ denotes the incompletely controlled increment of the pump-probe time delay. In what follows, the quantity $\Delta \tau=\tau-\tau_{0}$ will be supposed to exhibit a Gaussian distribution $P(\Delta \tau)=$ $(\beta / \pi)^{1 / 2} \exp \left[-(\Delta \tau)^{2}\right]$ in a given campaign of experiments; it may vary from one campaign to another. The signals $\Delta S[r, \tau], S(q, \tau)$ must thus be averaged over all possible realizations of the x-ray probe fields. Then, designating this averaged $x$-ray pulse intensity by $\left\langle I_{x}(t-\tau)\right\rangle$, we obtain

$\Delta S[r, \tau]=\int d t\left\langle I_{x}(t-\tau)\right\rangle \Delta S_{\mathrm{inst}}[r, t]$

$\Delta S(q, \tau)=\int d t\left\langle I_{x}(t-\tau)\right\rangle \Delta S_{\text {inst }}(q, t)$

where

$\left\langle I_{x}(t-\tau)\right\rangle=(\beta / \pi)^{1 / 2} I_{0} \times$

$\times \int d \Delta \tau \exp \left[-\alpha(t-\tau-\Delta \tau)^{2}\right] \exp \left[-\beta \Delta \tau^{2}\right]=$

$=[\beta / \alpha+\beta]^{1 / 2} I_{0} \exp \left(-[\alpha \beta /(\alpha+\beta)](t-\tau)^{2}\right)$.

It results from the above analysis that the fluctuations of the pump-probe time delay can be accounted for by simply replacing the true $\mathrm{x}$-ray probe pulse shape $I_{0} \exp \left[-\alpha(t-\tau)^{2}\right]$ by the effective x-ray pulse shape given by Eq. (8). This results in a small intensity change in the diffracted signal and a small broadening. The effects are rarely spectacular. For example, if the jitter in the pump-probe time delays amounts to $20 \%$ of the nominal temporal half-width of the probing x-ray pulse of $100 \mathrm{ps}$, the width of the effective $\mathrm{x}$-ray pulse increases only by 2 ps. If this spread is of $50 \%$, the effective pulse broadens for approximately $10 \mathrm{ps.} \mathrm{We} \mathrm{do} \mathrm{not} \mathrm{believe} \mathrm{that} \mathrm{the}$ Gaussian approximation affects the above results to any considerable extent.

\section{Conclusions}

Convolution problems are omnipresent in natural sciences. They also play an important role in spectroscopy and in time-resolved x-ray diffraction. Finite slit width problems of the first of these two techniques are replaced by those of finite $\mathrm{x}$-ray pulse duration in the second. Deconvolution techniques, needed to improve the experimental resolution, are similar in both these fields. The motional narrowing of spectral bands, well known in NMR and in optics, is present in x-ray diffraction too. It forbids visualizing the atomic motions during a chemical reaction, if x-ray pulses are not short enough. It should finally be noted that the convolution problems well-known in spectroscopy over many years are new in $\mathrm{x}$-ray physics.

This paper may be concluded, by reproducing the well-known statement, which remains more than ever of actuality (20): "Would you rather use the deconvolution or build a more highly resolving instrument? Generally, this is not a well-posed question. However, the answer, if both time and resources are unlimited, is to build a better instrument. If not, the deconvolution should be applied".

1. Deconvolution of Images and Spectra, edited by P.A. Janson, (Academic Press, New York, 1997).

2. W. Wallace, L.H. Schaeffer, and J.R. Swedlow, Bio Techniques, 31, 1076 (2001).

3. J.E. Diaz-Zamboni, E.V. Paravani, J.F. Adur, and V.H. Casco, Acta Microsc. 16, 8 (2007).

4. A. Meister, Deconvolution Problems in Nonparametric Statistics (Springer, Berlin, 2009).

5. Ch. Bressler and M. Chergui, Chem. Rev. 104, 1781 (2004).

ISSN 2071-0194. Ukr. J. Phys. 2012. Vol. 57, No. 2 
6. S. Bratos and M. Wulff, Adv. Chem. Phys. 317, 1 (2008).

7. M. Chergui and A.H. Zewail, Chem. Phys. Chem. 10, 28 (2009).

8. M. Ben-Nun, J. Cao, and K.R. Wilson, Phys. Chem. A 101, 8743 (1997).

9. R. Neutze and R. Wouts, J. of Synchr. Rad. 7, 22 (2000).

10. S. Bratos, F. Mirloup, R. Vuilleumier, and M. Wulff, J. Chem. Phys. 116, 10615 (2002).

11. J.P. Hansen and I.R. Mc Donald, Theory of Simple Liquids (Academic Press, New York, 2006).

12. M. Cammarata, M. Lorenc, T.K. Kim, J.H. Lee, Q.Y. Kong, E. Pontecorvo, M. Lo Russo, G. Schiró, A. Cupane, M. Wulff, and H. Ihee, J. Chem. Phys. 124, 124504 (2006).

13. A. Plech, M. Wulff, S. Bratos, F. Mirloup, R. Vuilleumier, F. Schotte, and P.A. Anfinrud, Phys. Rev. Lett. 92, 125505 (2004).

14. M. Wulff, S. Bratos, A. Plech, R. Vuilleumier, F. Mirloup, M. Lorenc, Q. Kong, and H. Ihee, J. Chem. Phys. 124, 034501 (2006).

15. Q.Y. Kong, J.H. Lee, M. Lo Russo, T.K. Kim, M. Lorenc, M. Cammarata, S. Bratos, Th. Buslaps, V. Honkimaki, H. Ihee, and M. Wulff, Acta Cryst. 124, 124504 (2010).

16. B.E. Warren, X-Ray Diffraction (Dover, New York, 1990).

17. D.F. Kelley, N.A. Abul-Haj, and Du-Jeon Jang, J. Chem. Phys. 80, 4105 (1984).

18. A.L. Harris, J.K. Brown, and C.B. Harris, Ann. Rev. Phys. Chem. 39, 341, (1988).
19. A. Abragam, Les Principes du Magnétisme Nucléaire (Univ. de France, Paris, 1961).

20. P.B. Crilly, W.E. Blass, and G.W. Halsey, in Deconvolution of Images and Spectra, edited by P.A. Janson (Academic Press, New York, 1997).

Received 29.10.11

\author{
ЗАДАЧІ КОНВОЛЮЦІї ДЛЯ ДИФРАКЦІї \\ РЕНТГЕНІВСЬКИХ ПРОМЕНІВ \\ 3 ЧАСОВИМ РОЗРІЗНЕННЯМ \\ С. Братос, Ж.-Кл. Лейкнем \\ $\mathrm{P}$ е $з$ ю м е
}

Теоретично досліджено задачі конволюції для розсіяння рентгенівських променів з тривалістю імпульсів 10-1000 пс. У ролі модельної системи вибрано розбавлену суміш діатомних молекул $\mathrm{A}_{2}$ в інертному розріджувачі. Система опромінюється субпікосекундними імпульсами лазера, що переводять молекули $\mathrm{A}_{2}$ в збуджений стан. При поверненні в основний стан молекула проходить через декілька проміжних станів. У рамках цієї моделі вивчено залежність різних рентгенівських сигналів від тривалості тестуючих рентгенівських імпульсів. Спочатку досліджено незміщені сигнали, які генеровані дуже короткими рентгенівськими імпульсами. При цьому чітко видно зміни геометрії молекул по $r$-розрізнених сигналах, і вони менше помітні при $q$-розрізненні. Потім вивчено сигнали, що генеровані рентгенівськими імпульсами скінченної тривалості. Рух атомів залишається помітним, якщо рентгенівські імпульси коротші чи порівнянні по тривалості з часом молекулярної динаміки. Тут також $r$-розрізнений сигнал більше підходить для моніторингу молекулярної динаміки, ніж q-розрізнені сигнали. Крім того, вивчено ефект недостатньої часової локалізації тестуючих рентгенівських імпульсів у порівнянні зі збуджуючими імпульсами лазера. Показано, що цей останній ефект може бути пояснений простою заміною реальної інтенсивності рентгенівського імпульсу іншою, теоретично передбачуваною інтенсивністю. Підкреслено схожість методів деконволюції у спектроскопії та у дифракції рентгенівських променів з часовим розрізненням. 